\title{
Pretreatment monocyte counts and neutrophil counts predict the risk for febrile neutropenia in patients undergoing TPF chemotherapy for head and neck squamous cell carcinoma
}

\begin{abstract}
Marie Shimanuki ${ }^{1}$, Yorihisa Imanishi ${ }^{1}$, Yoichiro Sato ${ }^{1}$, Nana Nakahara ${ }^{1}$, Daisuke Totsuka ${ }^{1}$, Emiri Sato ${ }^{1}$, Sena Iguchi ${ }^{1}$, Yasuo Sato ${ }^{2}$, Keiko Soma ${ }^{3}$, Yasutomo Araki ${ }^{1}$, Seiji Shigetomi ${ }^{4}$, Satoko Yoshida5, Kosuke Uno ${ }^{6}$, Yusuke Ogawa7, Takehiro Tominaga5, Yuichi Ikari ${ }^{5}$, Junko Nagayama ${ }^{4}$, Ayako Endo ${ }^{8}$, Koshiro Miura9, Takuya Tomioka ${ }^{10}$, Hiroyuki Ozawa ${ }^{5}$ and Kaoru Ogawa ${ }^{5}$

${ }^{1}$ Department of Otorhinolaryngology-Head and Neck Surgery, Kawasaki Municipal Kawasaki Hospital, Kawasaki, Kanagawa, Japan

${ }^{2}$ Department of Otorhinolaryngology, Kyosai Tachikawa Hospital, Tachikawa, Tokyo, Japan

${ }^{3}$ Department of Otorhinolaryngology, Matsumoto Dental University, Matsumoto, Nagano, Japan

${ }^{4}$ Department of Otorhinolaryngology, Yokohama Municipal Citizen's Hospital, Yokohama, Kanagawa, Japan

${ }^{5}$ Department of Otorhinolaryngology-Head and Neck Surgery, Keio University School of Medicine, Shinjuku, Tokyo, Japan

${ }^{6}$ Department of Otolaryngology-Head and Neck Surgery, National Defense Medical College, Tokorozawa, Saitama, Japan

${ }^{7}$ Department of Otorhinolaryngology, International University of Health and Welfare Atami Hospital, Atami, Shizuoka, Japan

${ }^{8}$ Department of Otorhinolaryngology, Saitama Red Cross Hospital, Saitama, Saitama, Japan

${ }^{9}$ Department of Otorhinolaryngology, Kamio Memorial Hospital, Chiyoda, Tokyo, Japan

${ }^{10}$ Department of Otorhinolaryngology, Ashikaga Red Cross Hospital, Ashikaga, Tochigi, Japan

Correspondence to: Yorihisa Imanishi, email: yorihisa@ja2.so-net.ne.jp

Keywords: febrile neutropenia; TPF; monocyte count; neutrophil count; head and neck squamous cell carcinoma

Received: February 09, $2018 \quad$ Accepted: March 07, $2018 \quad$ Published: April 10, 2018

Copyright: Shimanuki et al. This is an open-access article distributed under the terms of the Creative Commons Attribution License 3.0 (CC BY 3.0), which permits unrestricted use, distribution, and reproduction in any medium, provided the original author and source are credited.
\end{abstract}

\section{ABSTRACT}

Background: Febrile neutropenia (FN) is the most serious hematologic toxicity of systemic chemotherapy. However, accurate prediction of FN development has been difficult because the risk varies largely depending on the chemotherapy regimen and various individual factors.

Methods: We retrospectively analyzed diverse clinical factors including pretreatment hematological parameters to clarify the reliable predictors of $F \mathbf{N}$ development during chemotherapy with a docetaxel, cisplatin, and fluorouracil (TPF) regimen in patients with head and neck squamous cell carcinoma.

Results: Among the 50 patients, grade $\geq 3$ neutropenia, grade 4 neutropenia, and FN developed in $36(72 \%), 21(42 \%)$, and $12(24 \%)$ patients, respectively. Multivariate logistic regression revealed that a pretreatment absolute monocyte count (AMC) $<370 / \mathrm{mm}^{3}$ is an independent predictor of TPF chemotherapy-induced FN (odds ratio $=6.000, p=0.017$ ). The predictive performance of the model combining $A M C$ and absolute neutrophil count (ANC), in which the high-risk group was defined as having an AMC $<370 / \mathrm{mm}^{3}$ and/or ANC $<3500 / \mathrm{mm}^{3}$, was superior (area under the curve $[A U C]=0.745)$ to that of the model with a cutoff for AMC alone $(A U C=0.679)$.

Conclusions: On the basis of our results, we recommend primary prophylactic use of granulocyte colony-stimulating factor and/or antibiotics selectively for patients predicted to be at high risk for TPF chemotherapy-induced FN. 


\section{INTRODUCTION}

Neutropenia is one of the most common adverse effects of systemic anti-cancer chemotherapy and represents a major dose-limiting toxicity $[1,2]$. In particular, febrile neutropenia (FN), a condition in which fever develops in the presence of neutropenia, is the most serious hematologic toxicity because it may predispose patients to life-threatening infections such as severe sepsis and septic shock [3, 4]. In unselected cohorts, the risk for FN-related mortality was estimated to be as high as $5-11 \%$ [5]. The management of FN requires intensive antibacterial therapy with broad-spectrum antibiotics and prolonged hospitalization, leading to treatment delays and dose reductions of chemotherapy that potentially compromise treatment outcomes [1-4]. If the patients who are at a high risk for FN can be distinguished appropriately before chemotherapy, efficient prevention of $\mathrm{FN}$-induced serious infections can be feasible by precluding FN development via the administration of highly selective, prophylactic granulocyte colony-stimulating factor (G-CSF) to those at high risk for FN, as well as by avoiding unnecessary prescription of costly G-CSF and antibiotics to those at low risk for FN [4, 6, 7]. However, it has been difficult to accurately predict the development of $\mathrm{FN}$, because the extent and timing of neutropenia, as well as susceptibility to infection, vary widely among individuals, which depends on not only chemotherapy regimens but also various patient factors.

With regards to induction chemotherapy for advanced head and neck squamous cell carcinoma (HNSCC), a docetaxel, cisplatin, and fluorouracil-based regimen (TPF) has been shown to be superior to others in randomized phase III trials wherein a larynx preservation strategy was attempted [8-12]. According to these clinical trials involving patients with $\mathrm{HNSCC}$, the incidence of FN with regimens containing taxane and platinum ranges from $4.8 \%$ to $19 \%[8,9,13-16]$. Nonetheless, in community settings, previous studies have shown that the incidence of FN in patients treated with taxane and platinum-based regimens was as high as $34-55 \%$, and severe infections developed in $46-48 \%$ of the FN episodes $[17,18]$. These results suggest that even within the same regimens, the risk for FN and its resulting complications differ largely according to the patients' backgrounds and should be evaluated individually.

Previous studies on various malignancies have revealed that chemotherapy-induced FN involves diverse risk factors as follows: older age; poorer performance status; lower body weight; lower pretreatment blood cell counts that include white blood cells (WBCs), neutrophils, lymphocytes, and monocytes; presence of comorbidities involving major organs; advanced stage cancer; history of prior chemotherapy; higher dose intensity and number of cycles of chemotherapy [19-26]. However, differences in such significant predictors of FN among studies have largely depended on the cancer type and regimens applied. Concerning taxane and platinumbased regimens for patients with HNSCC, although only a few studies have been conducted, tube feeding, diabetes mellitus, and a high liver ultrasonography fibrotic score were identified as independent predictors of FN [17, 27]. Although pretreatment hematological parameters (i.e., WBC, neutrophil, lymphocyte, and monocyte counts) may directly reflect hematopoietic function and/or leukocyte counts in reservoirs within the body, no study has investigated the value of such hematological cell counts in the prediction of FN development exclusively in patients with HNSCC receiving TPF regimen.

We conducted this study to clarify the reliable predictors of FN development in patients with HNSCC who received TPF chemotherapy in a community setting by examining various clinical factors including pretreatment hematological cell counts.

\section{RESULTS}

\section{Patient characteristics}

The demographic and clinical characteristics of the 50 patients included in this study are summarized in Table 1. The median age was 65 years (range, 44-79 years), and the man-to-woman ratio was 22:3. The most common primary tumor site was the hypopharynx $(\mathrm{n}=25,50 \%)$, followed by the oropharynx $(\mathrm{n}=9,18 \%)$, larynx $(n=6,12 \%)$, and oro-hypopharynx $(n=4,8 \%)$. Most patients $(\mathrm{n}=45,90 \%)$ had stage IV disease. The most common comorbidities were hypertension $(\mathrm{n}=19$, $38 \%)$ and diabetes mellitus $(n=5,10 \%)$. Transnasal tube nutrition was initiated ahead of chemotherapy in 7 patients (14\%) owing to difficulty in oral intake. The reason for TPF chemotherapy was induction in the majority of the patients $(\mathrm{n}=45,90 \%)$, whereas that in the others $(\mathrm{n}=5$, $10 \%$ ) was first-line treatment for recurrent or metastatic disease.

\section{Pretreatment laboratory data}

The pretreatment hematological and biochemical data obtained prior to the first cycle of TPF chemotherapy are summarized in Table 2. For some variables, the total number of patients was less than 50 because some parameters had not been examined just before the first cycle in a few patients. The median values were used as the cutoff value for dichotomization of each variable in the following univariate analysis.

\section{Incidence of FN and other adverse effects}

The incidence of grade 3 or higher adverse effects in the first cycle of TPF chemotherapy are summarized in Table 3. FN developed in 12 of 50 patients (24\%), while 
Table 1: Patient characteristics $(\mathbf{N}=\mathbf{5 0})$

\begin{tabular}{|c|c|c|}
\hline Variables (continuous) & Median & (Range) \\
\hline Age (yrs) & 65 & (44-79) \\
\hline Height (cm) & 165 & $(150.3-183.5)$ \\
\hline Weight (kg) & 58.8 & $(38.6-89.9)$ \\
\hline $\operatorname{BSA}\left(m^{2}\right)$ & 1.64 & $(1.34-2.13)$ \\
\hline BMI $\left(\mathrm{kg} / \mathrm{m}^{2}\right)$ & 21.1 & (14.9-29.4) \\
\hline Variables (categorical) & No. of patients & $\%$ \\
\hline \multicolumn{3}{|l|}{ Sex } \\
\hline Men & 44 & 88 \\
\hline Women & 6 & 12 \\
\hline \multicolumn{3}{|l|}{ Primary tumor site } \\
\hline Tongue & 3 & 6 \\
\hline Oropharynx & 9 & 18 \\
\hline Hypopharynx & 25 & 50 \\
\hline Oro-hypopharynx & 4 & 8 \\
\hline Larynx & 6 & 12 \\
\hline Paranasal sinus & 1 & 2 \\
\hline Unknown & 2 & 4 \\
\hline \multicolumn{3}{|l|}{ T stage } \\
\hline T0 & 6 & 12 \\
\hline $\mathrm{T} 1$ & 2 & 4 \\
\hline $\mathrm{T} 2$ & 4 & 8 \\
\hline $\mathrm{T} 3$ & 15 & 30 \\
\hline $\mathrm{T} 4$ & 23 & 46 \\
\hline \multicolumn{3}{|l|}{ N stage } \\
\hline N0 & 8 & 16 \\
\hline N1 & 4 & 8 \\
\hline $\mathrm{N} 2 \mathrm{a}$ & 5 & 10 \\
\hline $\mathrm{N} 2 \mathrm{~b}$ & 10 & 20 \\
\hline $\mathrm{N} 2 \mathrm{c}$ & 18 & 36 \\
\hline N3 & 5 & 10 \\
\hline \multicolumn{3}{|l|}{ M stage } \\
\hline M0 & 45 & 90 \\
\hline M1 & 5 & 10 \\
\hline \multicolumn{3}{|l|}{ Stage } \\
\hline I & 0 & 0 \\
\hline II & 2 & 4 \\
\hline III & 3 & 6 \\
\hline IV & 45 & 90 \\
\hline & & (Continued $)$ \\
\hline
\end{tabular}




\begin{tabular}{lcc}
\hline Variables (categorical) & No. of patients & \% \\
\hline Smoking & 45 & 90 \\
Hypertension & 19 & 38 \\
Diabetes mellitus & 5 & 10 \\
Tube nutrition & 7 & 14 \\
Reason for chemotherapy & \multicolumn{2}{|}{} \\
$\quad$ Induction & 5 & 90 \\
$\quad$ First-line for R/M & \multicolumn{2}{|c}{} \\
Number of cycles & 18 & 10 \\
1 & 26 & 36 \\
2 & 3 & 52 \\
3 & 3 & 6 \\
4 & \multicolumn{2}{c}{6} \\
\hline
\end{tabular}

BSA, body surface area; BMI, body mass index; R/M, recurrence or metastasis.

Table 2: Pretreatment hematological and biochemical laboratory data

\begin{tabular}{|c|c|c|c|c|}
\hline Variables & Unit & $\mathbf{N}^{\mathbf{a}}$ & Median & (Range) \\
\hline WBC & $\left(/ \mathrm{mm}^{3}\right)$ & 50 & 6465 & (3200-13600) \\
\hline ANC & $\left(/ \mathrm{mm}^{3}\right)$ & 47 & 4677 & (2041-10350) \\
\hline ALC & $\left(/ \mathrm{mm}^{3}\right)$ & 47 & 1458 & (470-2998) \\
\hline $\mathrm{AMC}$ & $\left(/ \mathrm{mm}^{3}\right)$ & 47 & 532 & $(210-1655)$ \\
\hline Hemoglobin & $(\mathrm{g} / \mathrm{dL})$ & 50 & 13.15 & $(8.9-16.2)$ \\
\hline Platelet & $\left(10^{4} / \mathrm{mm}^{3}\right)$ & 50 & 24.75 & $(12.6-56.2)$ \\
\hline NLR & & 47 & 2.93 & $(0.88-10.68)$ \\
\hline PLR & & 47 & 0.018 & $(0.006-0.054)$ \\
\hline LMR & & 47 & 2.93 & $(0.71-10.30)$ \\
\hline Total bilirubin & $(\mathrm{mg} / \mathrm{dL})$ & 47 & 0.6 & $(0.2-2.2)$ \\
\hline AST & (IU/L) & 50 & 18.5 & $(5-115)$ \\
\hline ALT & (IU/L) & 50 & 14 & $(8-205)$ \\
\hline LDH & (IU/L) & 48 & 163 & $(109-403)$ \\
\hline BUN & $(\mathrm{mg} / \mathrm{dL})$ & 50 & 12 & $(3-24)$ \\
\hline Creatinine & $(\mathrm{mg} / \mathrm{dL})$ & 50 & 0.7 & $(0.4-1.2)$ \\
\hline $\mathrm{CCr}^{\mathrm{b}}$ & $(\mathrm{mL} / \mathrm{min})$ & 50 & 84.6 & $(50.1-168.7)$ \\
\hline Albumin & $(\mathrm{g} / \mathrm{dL})$ & 45 & 4.0 & $(2.8-4.6)$ \\
\hline CRP & $(\mathrm{mg} / \mathrm{dL})$ & 48 & 0.395 & $(0.01-7.02)$ \\
\hline
\end{tabular}

WBC, white blood cell; ANC, absolute neutrophil count; ALC, absolute lymphocyte count; AMC, absolute monocyte count; NLR, neutrophil-to-lymphocyte ratio; PLR, platelet-to-lymphocyte ratio; LMR, lymphocyte-to-monocyte ratio; AST, aspartate transaminase; ALT, alanine aminotransferase; LDH, lactate dehydrogenase ; BUN, blood urea nitrogen; $\mathrm{CCr}$, creatinine clearance; CRP, C-reactive protein.

${ }^{a}$ Numbers of the patients were less than 50 in some variables.

${ }^{\mathrm{b} C a l c u l a t e d ~ u s i n g ~ C o c k c r o f t-G a u l t ~ e q u a t i o n . ~}$ 
Table 3: Adverse effects in the first cycle of TPF chemotherapy (grade 3 or higher)

\begin{tabular}{lccc}
\hline Adverse effects & Criteria & No. of patients & \% \\
\hline Febrile neutropenia & $($ See footnote & \\
Neutropenia & $\mathrm{ANC}<1000 / \mathrm{mm}^{3}$ & 12 & 24 \\
Grade 4 neutropenia & $\mathrm{ANC}<500 / \mathrm{mm}^{3}$ & 36 & 72 \\
Anemia & $\mathrm{Hb}<8.0 \mathrm{~g} / \mathrm{dL}$ & 21 & 42 \\
Thrombocytopenia & Platelet $<5.0-2.5 \times 10^{4} / \mathrm{mm}^{3}$ & 3 & 6 \\
Diarrhea & Increase of $\geq 7$ stools per day over baseline & 1 & 2 \\
Hyponatremia & $\mathrm{Na}$ (sodium) $<130-120 \mathrm{mmol} / \mathrm{L}$ & 22 & 44 \\
Hypokalemia & $\mathrm{K}$ (potassium) $<3.0-2.5 \mathrm{mmol} / \mathrm{L}$ & 4 & 8 \\
Hyperkalemia & $\mathrm{K}$ (potassium) $>6.0-7.0 \mathrm{mmol} / \mathrm{L}$ & 1 & 2 \\
ALT increased & $>5.0-20.0 \times \mathrm{ULN}$ & 1 & 2 \\
Creatinine increased & $>3.0 \times$ baseline or $>3.0-6.0 \times \mathrm{ULN}$ & 2 & 4 \\
\hline
\end{tabular}

ALT, alanine aminotransferase; ANC, absolute neutrophil count; Hb, Hemoglobin; ULN, upper limits of normal. ${ }^{a}$ According to the Common Terminology Criteria for Adverse Effects version 4.0, except for febrile neutropenia. ${ }^{\mathrm{b}} \mathrm{A}$ combination of an occurrence of a fever with axillary temperature $\geq 37.5^{\circ} \mathrm{C}$ and an ANC of $<500 / \mathrm{mm}^{3}$ or that of $<1000$ / $\mathrm{mm}^{3}$ with a predicted decline to $<500 / \mathrm{mm}^{3}$ during the next 48 hours.

grade 3 or higher neutropenia was observed in 36 patients (72\%); grade 4 neutropenia occurred in 21 patients (42\%). Regarding non-hematological adverse effects, hyponatremia $(\mathrm{n}=22,44 \%)$ and diarrhea $(\mathrm{n}=13,26 \%)$ were most commonly observed. G-CSF was administered to 20 patients $(40 \%)$ who developed FN or grade 4 neutropenia, of whom antibiotics were administered to $14(28 \%)$ and treatment delay more than a week was necessitated due to severe infections in 3 patients $(6 \%)$.

\section{Univariate and multivariate analyses of predictors of FN development}

In the univariate analysis, we found that the pretreatment $\mathrm{WBC}$ count $(\mathrm{P}=0.044)$, absolute neutrophil count (ANC, $\mathrm{P}=0.020$ ), and absolute monocyte count (AMC, $\mathrm{P}=0.049$ ) were significantly correlated with $\mathrm{FN}$ development in the first cycle of TPF chemotherapy (Table 4). On the other hand, the other variables including age, body mass index, tumor-related stage, comorbidities, tube nutrition, absolute lymphocyte count, anemia, and hypoalbuminemia, showed no significant correlation with FN development.

Using receiver operating characteristic (ROC) curves, we determined the optimal cutoff values of the above-mentioned hematological variables as follows: $6500 / \mathrm{mm}^{3}$ for $\mathrm{WBC}, 3500 / \mathrm{mm}^{3}$ for $\mathrm{ANC}$, and $370 / \mathrm{mm}^{3}$ for $\mathrm{AMC}$; the area under the curve (AUC) for each variable is shown in Figure 1. The multivariate logistic regression model revealed that AMC $<370 / \mathrm{mm}^{3}$ was the only independently significant predictor of TPF chemotherapyinduced FN (odds ratio $=6.000$ [95\% confidence interval: $1.372-26.237]$ vs. $\mathrm{AMC} \geq 370 / \mathrm{mm}^{3}, \mathrm{P}=0.017$, Table 5 ).

\section{Diagnostic performance of the prediction of FN development}

To assess the clinical usefulness of the aforementioned significant predictors, we compared the diagnostic performance for the prediction of FN development between $\mathrm{AMC}$ alone and a combination of AMC and ANC in the evaluable 47 patients, by dichotomizing them into two groups (high-risk group vs. low-risk group) using the cutoff value of those variables as shown in Table 6. When an AMC of $370 / \mathrm{mm}^{3}$ was used as the cutoff value, the FN incidences in the high- and low-risk groups were $54.5 \%$ and $16.7 \%$, respectively $(\mathrm{P}=0.020)$. The sensitivity, specificity, positive likelihood ratio, negative likelihood ratio, and odds ratio in this model for prediction of FN development were $50.0 \%$, $85.7 \%, 3.50,0.58$, and 6.00 , respectively. On the other hand, when the low-risk group was defined as having an $\mathrm{AMC} \geq 370 / \mathrm{mm}^{3}$ and $\mathrm{ANC} \geq 3500 / \mathrm{mm}^{3}$ and the high-risk group was defined as the remainders (i.e., having an AMC $<370 / \mathrm{mm}^{3}$ and $/$ or ANC $<3500 / \mathrm{mm}^{3}$ ), the $\mathrm{FN}$ incidences in the high- and low-risk groups were $45.5 \%$ and $8.0 \%$, respectively $(\mathrm{P}=0.006)$. The sensitivity, specificity, positive likelihood ratio, negative likelihood ratio, and odds ratio in this model were $83.3 \%, 65.7 \%, 2.43,0.25$, and 9.58 , respectively. The distribution diagram of AMC and ANC showed a moderate linear association between $\mathrm{AMC}$ and $\mathrm{ANC}$, with a correlation coefficient of $\mathrm{r}=0.454$ $(\mathrm{P}=0.001$; Figure 2A). According to the ROC curves, the AUC of the latter model in which the cutoff was a combination of AMC and ANC was greater than that of the former model in which the cutoff involved AMC alone (0.745 vs. 0.679 , Figure $2 \mathrm{~B})$. 
Table 4: Univariate analysis of predictive factors of FN development

\begin{tabular}{|c|c|c|c|c|}
\hline \multirow{2}{*}{ Variables } & & \multicolumn{2}{|c|}{ No. of patients ${ }^{\mathrm{a}}$} & \multirow{2}{*}{ P value } \\
\hline & & FN+ & FN- & \\
\hline \multirow[t]{2}{*}{ Age (yrs) } & $\geq 65$ & 7 & 20 & 1.000 \\
\hline & $<65$ & 5 & 18 & \\
\hline \multirow[t]{2}{*}{ Sex } & Men & 12 & 32 & 0.314 \\
\hline & Women & 0 & 6 & \\
\hline \multirow[t]{2}{*}{ Height (cm) } & $\geq 165$ & 7 & 20 & 1.000 \\
\hline & $<165$ & 5 & 18 & \\
\hline \multirow[t]{2}{*}{ Weight (kg) } & $\geq 58.8$ & 7 & 19 & 0.745 \\
\hline & $<58.8$ & 5 & 19 & \\
\hline \multirow[t]{2}{*}{$\operatorname{BSA}\left(\mathrm{m}^{2}\right)$} & $\geq 1.64$ & 6 & 19 & 1.000 \\
\hline & $<1.64$ & 6 & 19 & \\
\hline \multirow[t]{2}{*}{ BMI $\left(\mathrm{kg} / \mathrm{m}^{2}\right)$} & $\geq 21.1$ & 6 & 20 & 1.000 \\
\hline & $<21.1$ & 6 & 18 & \\
\hline \multirow[t]{2}{*}{ Primary tumor site } & Hypopharynx & 7 & 22 & 1.000 \\
\hline & Others & 5 & 16 & \\
\hline \multirow[t]{2}{*}{ T stage } & $0-3$ & 7 & 20 & 1.000 \\
\hline & 4 & 5 & 18 & \\
\hline \multirow[t]{2}{*}{$\mathrm{N}$ stage } & 0 & 4 & 5 & 0.191 \\
\hline & $\geq 1$ & 8 & 33 & \\
\hline \multirow[t]{2}{*}{ M stage } & 0 & 10 & 35 & 0.582 \\
\hline & 1 & 2 & 3 & \\
\hline \multirow[t]{2}{*}{ Stage } & I-III & 0 & 5 & 0.319 \\
\hline & IV & 12 & 33 & \\
\hline \multirow[t]{2}{*}{ Brinkman index } & $\geq 820$ & 4 & 23 & 0.183 \\
\hline & $<820$ & 8 & 15 & \\
\hline \multirow[t]{2}{*}{ Hypertension } & Yes & 3 & 16 & 0.332 \\
\hline & No & 9 & 22 & \\
\hline \multirow[t]{2}{*}{ Diabetes mellitus } & Yes & 0 & 5 & 0.319 \\
\hline & No & 12 & 33 & \\
\hline \multirow[t]{2}{*}{ Tube nutrition } & Yes & 0 & 7 & 0.174 \\
\hline & No & 12 & 31 & \\
\hline \multirow[t]{2}{*}{ Reason for chemotherapy } & Induction & 11 & 34 & 1.000 \\
\hline & For $\mathrm{R} / \mathrm{M}$ & 1 & 4 & \\
\hline \multirow[t]{2}{*}{$\mathrm{WBC}\left(/ \mathrm{mm}^{3}\right)$} & $\geq 6465$ & 3 & 24 & 0.044 \\
\hline & $<6465$ & 9 & 14 & \\
\hline \multirow[t]{2}{*}{$\operatorname{ANC}\left(/ \mathrm{mm}^{3}\right)$} & $\geq 4677$ & 3 & 23 & 0.020 \\
\hline & $<4677$ & 9 & 12 & \\
\hline
\end{tabular}

(Continued) 


\begin{tabular}{|c|c|c|c|c|}
\hline \multirow{2}{*}{ Variables } & & \multicolumn{2}{|c|}{ No. of patients ${ }^{\mathrm{a}}$} & \multirow{2}{*}{ P value } \\
\hline & & FN+ & FN- & \\
\hline \multirow[t]{2}{*}{$\operatorname{ALC}\left(/ \mathrm{mm}^{3}\right)$} & $\geq 1458$ & 6 & 20 & 0.744 \\
\hline & $<1458$ & 6 & 15 & \\
\hline \multirow[t]{2}{*}{$\operatorname{AMC}\left(/ \mathrm{mm}^{3}\right)$} & $\geq 532$ & 3 & 21 & 0.049 \\
\hline & $<532$ & 9 & 14 & \\
\hline \multirow[t]{2}{*}{ Hemoglobin (g/dL) } & $\geq 13.15$ & 9 & 17 & 0.100 \\
\hline & $<13.15$ & 3 & 21 & \\
\hline \multirow[t]{2}{*}{ Platelet $\left(10^{4} / \mathrm{mm}^{3}\right)$} & $\geq 24.75$ & 5 & 22 & 0.508 \\
\hline & $<24.75$ & 7 & 16 & \\
\hline \multirow[t]{2}{*}{ NLR } & $\geq 2.93$ & 5 & 20 & 0.505 \\
\hline & $<2.93$ & 7 & 15 & \\
\hline \multirow[t]{2}{*}{ PLR } & $\geq 0.018$ & 5 & 20 & 0.505 \\
\hline & $<0.018$ & 7 & 15 & \\
\hline \multirow[t]{2}{*}{ LMR } & $\geq 2.93$ & 7 & 17 & 0.740 \\
\hline & $<2.93$ & 5 & 18 & \\
\hline \multirow[t]{2}{*}{ Total bilirubin $(\mathrm{mg} / \mathrm{dL})$} & $\geq 0.6$ & 7 & 18 & 0.747 \\
\hline & $<0.6$ & 5 & 17 & \\
\hline \multirow[t]{2}{*}{ AST (IU/L) } & $\geq 18.5$ & 4 & 21 & 0.321 \\
\hline & $<18.5$ & 8 & 17 & \\
\hline \multirow[t]{2}{*}{ ALT (IU/L) } & $\geq 14$ & 6 & 19 & 1.000 \\
\hline & $<14$ & 6 & 19 & \\
\hline \multirow[t]{2}{*}{ LDH (IU/L) } & $\geq 163$ & 6 & 20 & 0.751 \\
\hline & $<163$ & 6 & 16 & \\
\hline \multirow[t]{2}{*}{ BUN (mg/dL) } & $\geq 12$ & 5 & 23 & 0.324 \\
\hline & $<12$ & 7 & 15 & \\
\hline \multirow[t]{2}{*}{ Creatinine (mg/dL) } & $\geq 0.7$ & 7 & 20 & 1.000 \\
\hline & $<0.7$ & 5 & 18 & \\
\hline \multirow[t]{2}{*}{$\mathrm{CCr}(\mathrm{mL} / \mathrm{min})$} & $\geq 84.6$ & 8 & 17 & 0.321 \\
\hline & $<84.6$ & 4 & 21 & \\
\hline \multirow[t]{2}{*}{ Albumin (g/dL) } & $\geq 4.0$ & 7 & 19 & 0.736 \\
\hline & $<4.0$ & 4 & 15 & \\
\hline \multirow[t]{2}{*}{$\mathrm{CRP}(\mathrm{mg} / \mathrm{dL})$} & $\geq 0.395$ & 4 & 20 & 0.318 \\
\hline & $<0.395$ & 8 & 16 & \\
\hline
\end{tabular}

FN, febrile neutropenia; BSA, body surface area; BMI, body mass index; R/M, recurrence or metastasis; WBC, white blood cell; ANC, absolute neutrophil count; ALC, absolute lymphocyte count; AMC, absolute monocyte count; NLR, neutrophilto-lymphocyte ratio; PLR, platelet-to-lymphocyte ratio; LMR, lymphocyte-to-monocyte ratio; AST, aspartate transaminase; ALT, alanine aminotransferase; LDH, lactate dehydrogenase ; BUN, blood urea nitrogen; CCr, creatinine clearance; CRP, C-reactive protein.

${ }^{a}$ Numbers of the patients in total were less than 50 in some variables of hematological and biochemical laboratory data as shown in Table 2. 


\section{DISCUSSION}

In the present study, we found that neutropenia was the most frequent grade 3 or higher adverse effect (72\%) to occur in the cohort of patients with HNSCC who underwent TPF chemotherapy. Notably, the incidence of FN was $24 \%$, which is consistent with that reported in recent studies conducted in a community setting similar to ours [27, 28], but apparently higher than those observed in clinical trials $(4.8-19 \%)$ [8, 9, 13-16]. This inconsistency is likely attributable to differences in the backgrounds of the patient cohorts, because those selected for clinical trials inevitably tend to be in better health since they are younger, and demonstrate a better performance status and no severe comorbidities or history of prior cancer treatments. In addition, even within a community setting, much higher incidences of FN (34-55\%) have also been reported in previous studies wherein the majority of the patients treated with taxane and platinum-based chemotherapy already had received prior chemotherapy and radiotherapy $[17,18]$. These observations suggest a limitation of a regimen-based prediction of chemotherapyinduced FN and the importance of the addition of an individual characteristics-based prediction strategy in realworld clinical practice.

The present study, in which we assessed the association between pretreatment hematological parameters and FN development exclusively in patients with HNSCC for the first time, demonstrated that pretreatment $\mathrm{AMC}$ is an independent risk factor predictive of FN development in HNSCC patients who underwent TPF chemotherapy. Moreover, although the correlation between pretreatment ANC and FN development was not shown to be independently significant, the prediction model comprising a combination of AMC and ANC in which the high-risk group was defined as having an
AMC $<370 / \mathrm{mm}^{3}$ and $/$ or ANC $<3500 / \mathrm{mm}^{3}$ demonstrated a superior diagnostic performance in the prediction of FN development when compared to that of the model comprising AMC alone. Even in terms of cancers other than HNSCC, only a limited number of previous studies have examined the correlation between pretreatment AMC and FN development using a multivariate analysis $[20,21,26]$. Among them, in accordance with our results, Moreau et al. reported that a baseline monocyte count $<150 / \mathrm{mm}^{3}$ is one of the independent predictors of FN in patients with hematological malignancies to whom more than 100 regimens were administered [21]. However, two other studies showed no correlation between the pretreatment AMC and FN development in patients with various hematological and solid tumors [20, 26]. Another study reported that incorporating the pretreatment AMC into a FN prediction model that consists of pretreatment ANC and the absolute lymphocyte count could improve the predictive ability, even though the pretreatment AMC alone showed no significant association with FN, in patients with early-stage breast cancer [29]. These inconsistent results are thought to be attributable to variances not only in the patients' background, including the type of cancer, but also in the regimens applied.

Regarding the physiologic mechanism of hematopoiesis, both neutrophils and monocytes differentiate from common myeloid progenitor cells, granulocyte-macrophage (GM) colony forming cells derived from multipotential hematopoietic stem cells, whereas lymphocytes have no direct progenitors in common with neutrophils [30]. This differentiation system can in part explain the close association between neutropenia and monocytopenia induced during chemotherapy. In addition, monocytes play a key role in promoting proliferation, differentiation, survival, and activation of both neutrophils and monocytes/
A

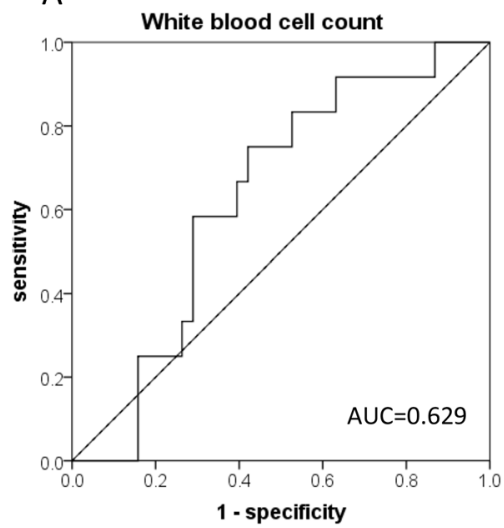

B

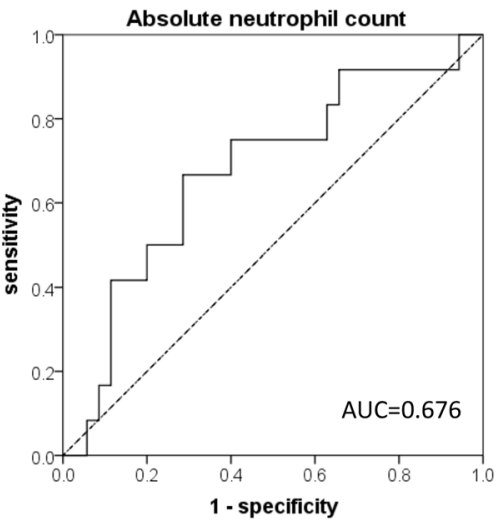

C

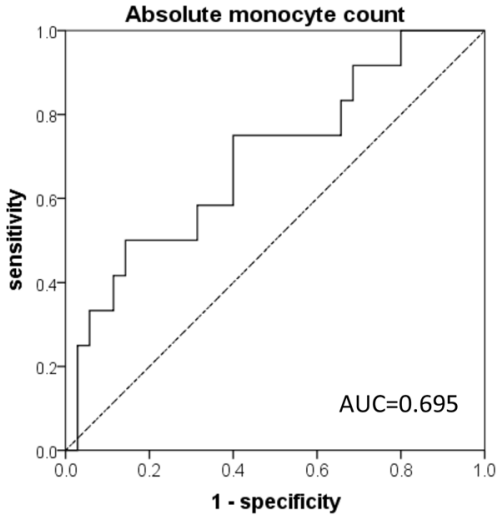

Figure 1: The receiver operator characteristic (ROC) curves for the prediction of febrile neutropenia (FN) development for (A) pretreatment white blood cell count (WBC), (B) absolute neutrophil count (ANC), and (C) absolute monocyte count (AMC). The areas under the curve (AUC) were 0.629 for $\mathrm{WBC}, 0.676$ for $\mathrm{ANC}$, and 0.695 for AMC. 
Table 5: Logistic regression model of predictive factors of FN development

\begin{tabular}{|c|c|c|c|c|c|}
\hline Step & Covariate & Dichotomization & Odds ratio & $95 \%$ confidence interval & P value \\
\hline \multirow[t]{3}{*}{1} & WBC & $\left(<6500 / \mathrm{mm}^{3}\right.$ vs. $\left.\geq 6500 / \mathrm{mm}^{3}\right)$ & 0.999 & $(0.068-14.788)$ & 1.000 \\
\hline & ANC & $\left(<3500 / \mathrm{mm}^{3}\right.$ vs. $\left.\geq 3500 / \mathrm{mm}^{3}\right)$ & 3.757 & $(0.303-46.643)$ & 0.303 \\
\hline & $\mathrm{AMC}$ & $\left(<370 / \mathrm{mm}^{3}\right.$ vs. $\left.\geq 370 / \mathrm{mm}^{3}\right)$ & 4.427 & $(0.885-22.150)$ & 0.070 \\
\hline \multirow[t]{2}{*}{2} & ANC & $\left(<3500 / \mathrm{mm}^{3}\right.$ vs. $\left.\geq 3500 / \mathrm{mm}^{3}\right)$ & 3.755 & $(0.851-16.557)$ & 0.081 \\
\hline & $\mathrm{AMC}$ & $\left(<370 / \mathrm{mm}^{3}\right.$ vs. $\left.\geq 370 / \mathrm{mm}^{3}\right)$ & 4.426 & $(0.935-20.949)$ & 0.061 \\
\hline 3 & $\mathrm{AMC}$ & $\left(<370 / \mathrm{mm}^{3}\right.$ vs. $\left.\geq 370 / \mathrm{mm}^{3}\right)$ & 6.000 & $(1.372-26.237)$ & 0.017 \\
\hline
\end{tabular}

FN, febrile neutropenia; WBC, white blood cell; ANC, absolute neutrophil count; AMC, absolute monocyte count.

Table 6: Comparison of predictive performance of $\mathrm{FN}$ development between $\mathrm{AMC}$ and $\mathrm{AMC}+\mathrm{ANC}(\mathrm{N}=47)$

\begin{tabular}{|c|c|c|c|c|c|c|c|c|c|c|}
\hline \multirow[b]{2}{*}{ Dichotomization } & \multicolumn{5}{|c|}{ AMC } & \multicolumn{5}{|c|}{$\mathrm{AMC}+\mathrm{ANC}$} \\
\hline & \multicolumn{5}{|c|}{$\begin{array}{l}\text { High risk: } \mathrm{AMC}<370 / \mathrm{mm}^{3} \\
\text { Low risk: } \mathrm{AMC} \geq 370 / \mathrm{mm}^{3}\end{array}$} & \multicolumn{5}{|c|}{$\begin{array}{l}\text { High risk: } A M C<370 / \mathrm{mm}^{3} \text { and } / \text { or } A N C<3500 / \mathrm{mm}^{3} \\
\text { Low risk: } A M C \geq 370 / \mathrm{mm}^{3} \text { and } A N C \geq 3500 / \mathrm{mm}^{3}\end{array}$} \\
\hline \multirow{4}{*}{ Two by two contingency tables } & $\mathrm{AMC}$ & $\mathrm{FN}+$ & FN- & Total & $\begin{array}{c}\mathrm{FN} \\
\text { incidence }\end{array}$ & $\mathrm{AMC}+\mathrm{ANC}$ & $\mathrm{FN}+$ & FN- & Total & $\begin{array}{c}\mathrm{FN} \\
\text { incidence }\end{array}$ \\
\hline & High risk & 6 & 5 & 11 & $54.5 \%$ & High risk & 10 & 12 & 22 & $45.5 \%$ \\
\hline & Low risk & 6 & 30 & 36 & $16.7 \%$ & Low risk & 2 & 23 & 25 & $8.0 \%$ \\
\hline & Total & 12 & 35 & 47 & & Total & 12 & 35 & 47 & \\
\hline Fisher's exact test & \multicolumn{5}{|c|}{$\mathrm{P}=0.020$} & \multicolumn{5}{|c|}{$\mathrm{P}=0.006$} \\
\hline Diagnostic performance & \multicolumn{2}{|c|}{ Value } & \multicolumn{3}{|c|}{$(95 \% \mathrm{CI})$} & \multicolumn{2}{|c|}{ Value } & \multicolumn{3}{|c|}{$(95 \% \mathrm{CI})$} \\
\hline Sensitivity & \multicolumn{2}{|c|}{$50.0 \%$} & \multicolumn{3}{|c|}{$(28.5-68.5 \%)$} & \multicolumn{2}{|c|}{$83.3 \%$} & \multicolumn{3}{|c|}{$(59.3-95.1 \%)$} \\
\hline Specificity & \multicolumn{2}{|c|}{$85.7 \%$} & \multicolumn{3}{|c|}{$(78.3-92.1 \%)$} & \multicolumn{2}{|c|}{$65.7 \%$} & \multicolumn{3}{|c|}{$(57.5-69.8 \%)$} \\
\hline Positive predictive value & \multicolumn{2}{|c|}{$54.5 \%$} & \multicolumn{3}{|c|}{$(31.1-74.8 \%)$} & \multicolumn{2}{|c|}{$45.5 \%$} & \multicolumn{3}{|c|}{$(32.4-51.9 \%)$} \\
\hline Negative predictive value & \multicolumn{2}{|c|}{$83.3 \%$} & \multicolumn{3}{|c|}{$(76.2-89.5 \%)$} & \multicolumn{2}{|c|}{$92.0 \%$} & \multicolumn{3}{|c|}{$(80.5-97.7 \%)$} \\
\hline Positive likelihood ratio & \multicolumn{2}{|c|}{3.50} & \multicolumn{3}{|c|}{$(1.32-8.64)$} & \multicolumn{2}{|c|}{2.43} & \multicolumn{3}{|c|}{$(1.40-3.14)$} \\
\hline Negative likelihood ratio & \multicolumn{2}{|c|}{0.58} & \multicolumn{3}{|c|}{$(0.34-0.91)$} & \multicolumn{2}{|c|}{0.25} & \multicolumn{3}{|c|}{$(0.07-0.71)$} \\
\hline Odds ratio & & & & $(1.44-25.26)$ & & 9. & & & $(1.97-44$ & \\
\hline AUC & & & & $(0.488-0.869)$ & & 0.7 & & & $(0.588-0$. & \\
\hline
\end{tabular}

FN, febrile neutropenia; AMC, absolute monocyte count; ANC, absolute neutrophil count; CI, confidence interval; AUC, area under the curve.

macrophages themselves by producing GM-CSF, G-CSF, macrophage-CSF, and other cytokines, in both paracrine and autocrine manners [31-34]. These underlying mechanisms can account for why decreased pretreatment AMC indirectly reflects lower hematopoietic function of the bone marrow that inevitably worsens the extent of chemotherapy-induced neutropenia. Monocytes and macrophages play critical roles in the innate immune system principally through phagocytosis and the release of inflammatory cytokines, and also help initiate the acquired immune system response by presenting antigens to recruit other immune cells such as lymphocytes $[35,36]$. Thus, decreased pretreatment AMC may also reflect suppressed immune function that can increase the susceptibility to infection. Taken together, lower pretreatment AMC is thought to be predictive of FN development presumably through a subclinical decline in both hematopoietic function and immune function.

During the course of chemotherapy-induced leukocytopenia, AMC is empirically known to precede ANC in terms of its onset, nadir, and recovery, as recently confirmed by Moriyama et al. who also reported a moderate correlation between $\mathrm{AMC}$ at the preceding nadir and ANC at the following nadir during platinum-based chemotherapy for lung cancer patients [37]. This phenomenon can be explained in part by the study that investigated the difference in the cell division history between these cells during their differentiation 
using a murine model, in which GM progenitors were demonstrated to generate postmitotic monocytes earlier than mature neutrophils [38]. Concerning the predictive ability of the post-treatment monocyte count measured during the early phases of chemotherapy, Kondo et al. first reported that an AMC $<150 / \mathrm{mm}^{3}$ on days 6 to 8 is a possible predictor of grade 3 or 4 neutropenia during cisplatin-based chemotherapy for advanced lung cancer [39], while Oguz et al. revealed an AMC $\leq 150 / \mathrm{mm}^{3}$ on day 7 is an independent risk factor for $\mathrm{FN}$ in various chemotherapy regimens for childhood solid tumors [40]. In support of these results, by analyzing the posttreatment hematological data in the same cohort of the present study, we also found that an $\mathrm{AMC} \leq 66 / \mathrm{mm}^{3}$ on days 3 to 5 is an independent risk factor of FN (data not shown). Nonetheless, considering the possible preparation required to prevent $\mathrm{FN}$ such as dose reduction of anticancer drugs and prophylactic use of antibiotics and/or G-CSF, the assessment of FN risk before chemotherapy using pretreatment information is thought to be more practical than that after chemotherapy using post-treatment information.

Neutrophils play a major role in the front-line host defense against invading micro-organisms by directly attacking pathogens via three mechanisms: phagocytosis, degranulation (release of soluble anti-microbials), and generation of neutrophil extracellular traps, in addition to recruiting and activating other immune cells by releasing various cytokines [41]. Therefore, decreased pretreatment ANC is also thought to reflect insufficiency in immune function as well as hematopoietic function, which could be predictive of FN development. However, among the previous studies that examined the predictive ability of pretreatment ANC, rather interestingly, only a few studies found pretreatment ANC to be a predictive factor of FN development $[21,42]$ or initial hospitalization due to FN [43] at least in the univariate analysis in line with our result, whereas other studies showed no association between them [26, 29, 44-48]. Neutrophils have been known to be activated and/or to increase in cell count in response to not only bacterial infection but also various other conditions including tissue injury after ischemia, administration of corticosteroids, hemodialysis, and smoking [41, 49-51], which may underestimate the potential suppression of hematopoietic and/or immune function. Hence, variances in the extent of heterogeneity of those comorbidity factors among the study cohorts could be a feasible explanation for the aforementioned inconsistent results. Namely, because those factors were relatively homogeneous in our cohort, in which no patients had co-morbidities that would induce noticeable neutrophilia except for a few patients while the vast majority had a smoking habit, pretreatment ANC in our study was thought to more evenly reflect hematopoietic and immune functions. Regardless of aforementioned variances among patient cohorts, we must be cautious when interpreting the ANC value because of its complex regulatory mechanisms as discussed above. Even if ANC remains within the normal range, we should be aware of the possible co-existence of both declined hematopoietic and/or immune function resulting in neutropenia and comorbidities leading to reactive neutrophilia, since these can offset one another's effect on ANC and/or WBC count.

According to three previous studies that focused exclusively on FN in HNSCC patients who received a docetaxel plus platinum-based chemotherapy, tube feeding, diabetes mellitus [17], and a high liver ultrasound fibrotic score [27] were demonstrated as independent
A

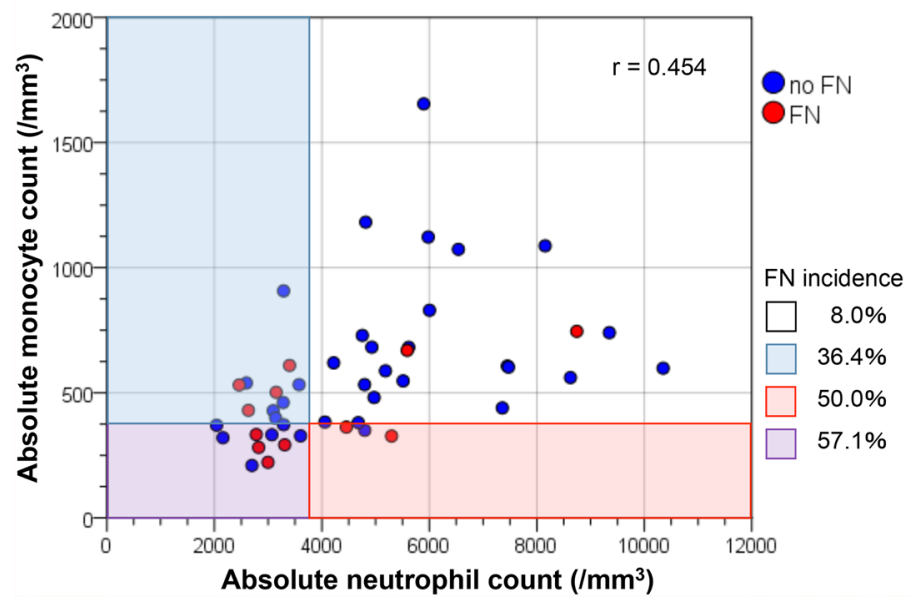

B

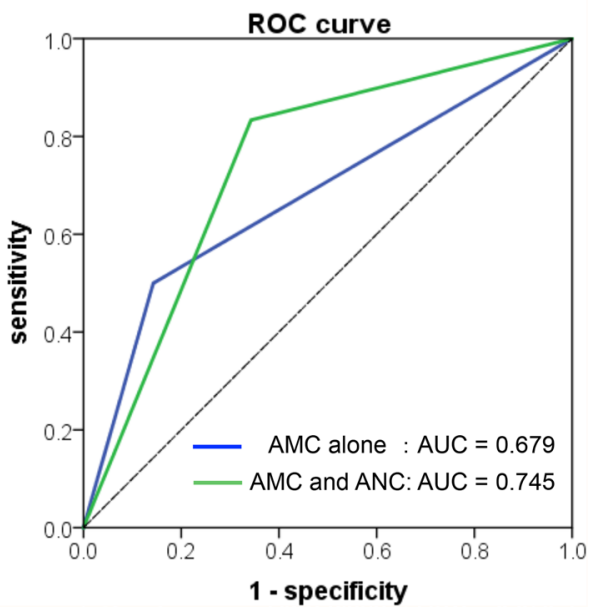

Figure 2: (A) The distribution diagram of absolute monocyte count (AMC) and absolute neutrophil count (ANC). Red circles indicate the patients who developed febrile neutropenia $(\mathrm{FN})$ and blue circles indicate those without $\mathrm{FN}$, which suggest a moderate linear association with a correlation coefficient of $\mathrm{r}=0.454(\mathrm{P}=0.001)$. (B) A comparison of receiver operator characteristic ( $\mathrm{ROC}$ ) curves between AMC alone (blue, $\mathrm{AUC}=0.679$ ) and a combination of $\mathrm{AMC}$ and $\mathrm{ANC}$ (green, $\mathrm{AUC}=0.745$ ) using the optimal cutoff value of those variables. 
factors predictive of FN, while tube feeding and a higher modified Charlson co-morbidity index were shown as independent predictors of severe infections [18]. In general, patients with locally advanced HNSCC tend to have difficulty with oral ingestion because of the close association between the anatomical location and swallowing function, which further tends to result in poor nutritional status (e.g., hypoalbuminemia) and necessity of tube feeding. However, such factors were not found to be predictive of $\mathrm{FN}$ in the present study, inconsistent with the previous studies conducted within a community setting $[17,18]$. Tube feeding is known to deteriorate the risk for diarrhea and aspiration pneumonia, but otherwise can stably provide adequate nutrition. Therefore, the possible disparity in the resultant imbalance between such undesired risks and beneficial effects among the studies could in part explain the above-mentioned inconsistent results. Moreover, although diabetes mellitus and other comorbidities were not found to be predictors of FN in our study either, such inconsistency could be attributed to differences in the extent of severity of those diseases and how they were appropriately controlled before chemotherapy.

In our cohort, G-CSF was administered in principle for therapeutic purposes (in patients with severe neutropenia or FN), because its prophylactic use had not been approved until 2013 per the Japanese medical insurance system. In our experience, therapeutic administration of G-CSF still fortunately has been able to prevent a majority of the patients with $\mathrm{FN}$ from developing serious infections such as severe sepsis and septic shock, although this type of G-CSF use has not been recommended by international guidelines [15, 52]. Since the Japanese practice guidelines were also revised in 2013 to allow for the use of primary prophylactic G-CSF in chemotherapy regimens wherein the risk of FN incidence is over $20 \%$ [53], currently, primary prophylaxis may be permissible in Japan as long as the patients undergo TPF chemotherapy in a community setting. Nonetheless, in terms of the cost-effectiveness, unconditional prophylactic use of expensive G-CSF in all these patients would not be ideal despite the high risk $(20-30 \%)$ of $\mathrm{FN}$ incidence. Hence, it is crucial to identify patients at higher risk for FN prior to chemotherapy and to prevent them from developing FN more efficiently via selective prophylactic administration of G-CSF. On the basis of the present results, we recommend primary prophylaxis against $\mathrm{FN}$ via the administration of G-CSF selectively to patients predicted to be at high risk for TPF chemotherapy-induced $\mathrm{FN}$ according to a dependable prediction model.

There are several limitations in our study, most of which are due to its retrospective nature. First, even in a community setting, patients with a poor performance status or serious medical illnesses were not scheduled to receive the TPF regimen although the criteria were not as strict as those of the clinical trials, which may lead to bias in terms of patient selection. Even within the patients who underwent TPF chemotherapy, the dose was reduced owing to hepatic or renal disorders. Therefore, our results may have underestimated the risk for TPF chemotherapyinduced FN. Second, because of the relatively small sample size in our cohort, the statistical power might not be enough to identify the significance of other possible predictive factors. However, considering the well-known wide variance in predictors across different regimens, it is valuable to elucidate the predictors of FN development exclusively in patients receiving the TPF regimen. Third, since we failed to examine some hematological parameters just before the first cycle in a few patients, missing values remained in several variables, which might have resulted in a biased data collection. Fourth, because we did not validate our prediction model using an external dataset, a prospective trial or a validation study will be indispensable to corroborate the reliability of its predictive performance.

In conclusion, the present study demonstrated that a pretreatment $\mathrm{AMC}<370 / \mathrm{mm}^{3}$ is an independent predictor of TPF chemotherapy-induced $\mathrm{FN}$ in patients with HNSCC. In addition, the prediction model comprising a combination of pretreatment $\mathrm{AMC}$ and $\mathrm{ANC}$, in which the high-risk group was defined as having an $\mathrm{AMC}<370 / \mathrm{mm}^{3}$ and/or ANC $<3500 / \mathrm{mm}^{3}$, yielded a superior predictive performance. Therefore, primary prophylaxis for $\mathrm{FN}$ via administration of G-CSF and/or antibiotics should be selectively considered for patients at high risk for FN according to the aforementioned prediction model.

\section{PATIENTS AND METHODS}

\section{Patients and data collection}

We retrospectively reviewed the medical records of patients with HNSCC who received TPF chemotherapy from January 2010 through December 2016 at the Department of Otorhinolaryngology-Head and Neck Surgery, Kawasaki Municipal Kawasaki Hospital. The Institutional Review Board and Research Ethics Committee approved the study protocol (reference numbers: 2017-10). The requirement for informed consent was waived owing to the retrospective nature of the analysis.

In total, 52 patients underwent TPF chemotherapy at least once or more during the aforementioned period. Two patients were excluded from the analysis because of prophylactic use of G-CSF in the first cycle of TPF chemotherapy in consideration of the apparently high probability of FN. The remaining 50 patients were enrolled in the study. We extracted the information that could be associated with development of FN from the medical charts. Patient characteristics included age, sex, body height, body weight, body mass index, and smoking 
status (Brinkman index). Disease characteristics included primary tumor site, TNM stage according to the UICC TNM classification and staging system (7th edition, 2010), and co-existing morbidities. Treatment factors included reason for chemotherapy and necessity of tube nutrition. Pretreatment hematological and biochemical data were obtained from laboratory blood examination tests performed within 2 weeks before the first cycle of the chemotherapy. The neutrophil-to-lymphocyte ratio, platelet-to-lymphocyte ratio, and lymphocyte-to-monocyte ratio were calculated by dividing absolute values of the corresponding blood cell counts.

\section{TPF chemotherapy and adverse effect evaluation}

All patients were administered a 1-hour intravenous infusion of docetaxel $\left(60 \mathrm{mg} / \mathrm{m}^{2}\right)$ on day 1 , a 3-hour intravenous infusion of cisplatin $\left(60 \mathrm{mg} / \mathrm{m}^{2}\right)$ on day 1 , and a continuous 24-hour infusion of fluorouracil (700 $\mathrm{mg} / \mathrm{m}^{2}$ ) on days $1-4$, except for 4 patients who required dose reduction because of hepatic or renal disorders. All patients were hospitalized for approximately 3 weeks to undergo TPF chemotherapy together with supportive care for the related adverse effects. Laboratory blood tests were performed twice or three times per week to identify hematopenia including neutropenia, electrolyte imbalance, and other adverse effects.

Chemotherapy-related adverse effects were evaluated according to the Common Terminology Criteria for Adverse Effects version 4.0, except for FN. For the purpose of this study, we defined $\mathrm{FN}$ as a combination of an occurrence of a fever with an axillary temperature $\geq 37.5^{\circ} \mathrm{C}$ and a neutrophil count of $<500 / \mathrm{mm}^{3}$ or that of $<1000 / \mathrm{mm}^{3}$ with a predicted decline to $<500 / \mathrm{mm}^{3}$ during the next 48 hours, as suggested by the Japanese Society of Medical Oncology, because body temperature is measured under the axilla in Japan and the axillary temperature is approximately $0.5^{\circ} \mathrm{C}$ below the oral temperature. We also documented the use of G-CSF and antibiotics, which were not for primary prophylactic purposes but for therapeutic purposes only.

\section{Statistical analysis}

Patient characteristics, disease characteristics, treatment factors, and pretreatment hematological and biochemical data were examined for their correlation with the development of chemotherapy-induced FN in the first cycle using the two-tailed Fisher's exact test. The continuous variables were dichotomized with the cutoff values using the median values. The independent significance of the variables detected to be significant in the univariate analysis was further assessed via a multivariate logistic regression analysis with the backward stepwise selection method, in which the optimal cutoff values were determined using the Youden index of the ROC curve. The diagnostic performance of the significant variables in the prediction of $\mathrm{FN}$ development was evaluated using two by two contingency tables and the AUC determined on the basis of the ROC curve. A linear association between paired continuous variables was evaluated using Pearson's correlation coefficient. P-values $<0.05$ were considered statistically significant. All analyses were carried out using SPSS version 24.0 (SPSS, Chicago, IL).

\section{Abbreviations}

FN: febrile neutropenia; TPF: docetaxel, cisplatin, and fluorouracil; AMC: absolute monocyte count; ANC: absolute neutrophil count; G-CSF: granulocyte colonystimulating factor; HNSCC: head and neck squamous cell carcinoma; WBC: white blood cells; ROC: receiver operating characteristic; AUC: area under the curve; GM: granulocyte-macrophage.

\section{ACKNOWLEDGMENTS}

The authors thank Editage (www.editage.jp) for English language editing.

\section{CONFLICTS OF INTEREST}

The authors have no relevant conflicts of interest to disclose.

\section{FUNDING}

This work was supported in part by the Grants-inAid for Scientific Research (C) from The Japan Society for the Promotion of Science (No.16K11245).

\section{REFERENCES}

1. Crawford J, Dale DC, Lyman GH. Chemotherapy-induced neutropenia: risks, consequences, and new directions for its management. Cancer. 2004; 100:228-237.

2. Lyman GH, Lyman $\mathrm{CH}$, Agboola O. Risk models for predicting chemotherapy-induced neutropenia. Oncologist. 2005; 10:427-437.

3. Jeddi R, Achour M, Amor RB, Aissaoui L, Bouteraa W, Kacem K, Lakhal RB, Abid HB, BelHadjAli Z, Turki A, Meddeb B. Factors associated with severe sepsis: prospective study of 94 neutropenic febrile episodes. Hematology. 2010; 15:28-32.

4. Renner P, Milazzo S, Liu JP, Zwahlen M, Birkmann J, Horneber M. Primary prophylactic colony-stimulating factors for the prevention of chemotherapy-induced febrile neutropenia in breast cancer patients. Cochrane Database Syst Rev. 2012; 10:CD007913. 
5. Kuderer NM, Dale DC, Crawford J, Lyman GH. Impact of primary prophylaxis with granulocyte colony-stimulating factor on febrile neutropenia and mortality in adult cancer patients receiving chemotherapy: a systematic review. J Clin Oncol. 2007; 25:3158-3167.

6. Cherif H, Bjorkholm M, Engervall P, Johansson P, Ljungman P, Hast R, Kalin M. A prospective, randomized study comparing cefepime and imipenem-cilastatin in the empirical treatment of febrile neutropenia in patients treated for haematological malignancies. Scand J Infect Dis. 2004; 36:593-600.

7. Timmer-Bonte JN, Adang EM, Smit HJ, Biesma B, Wilschut FA, Bootsma GP, de Boo TM, TjanHeijnen VC. Cost-effectiveness of adding granulocyte colony-stimulating factor to primary prophylaxis with antibiotics in small-cell lung cancer. J Clin Oncol. 2006; 24:2991-2997.

8. Posner MR, Hershock DM, Blajman CR, Mickiewicz E, Winquist E, Gorbounova V, Tjulandin S, Shin DM, Cullen K, Ervin TJ, Murphy BA, Raez LE, Cohen RB, et al. Cisplatin and fluorouracil alone or with docetaxel in head and neck cancer. N Engl J Med. 2007; 357:1705-1715.

9. Vermorken JB, Remenar E, van Herpen C, Gorlia T, Mesia R, Degardin M, Stewart JS, Jelic S, Betka J, Preiss JH, van den Weyngaert D, Awada A, Cupissol D, et al. Cisplatin, fluorouracil, and docetaxel in unresectable head and neck cancer. N Engl J Med. 2007; 357:1695-1704.

10. Lorch JH, Goloubeva O, Haddad RI, Cullen K, Sarlis N, Tishler R, Tan M, Fasciano J, Sammartino DE, Posner MR, and TAX 324 Study Group. Induction chemotherapy with cisplatin and fluorouracil alone or in combination with docetaxel in locally advanced squamous-cell cancer of the head and neck: long-term results of the TAX 324 randomised phase 3 trial. Lancet Oncol. 2011; 12:153-159.

11. Janoray G, Pointreau Y, Garaud P, Chapet S, Alfonsi M, Sire C, Jadaud E, Calais G. Long-term Results of a Multicenter Randomized Phase III Trial of Induction Chemotherapy With Cisplatin, 5-fluorouracil, +/- Docetaxel for Larynx Preservation. J Natl Cancer Inst. 2016; 108.

12. Winquist E, Agbassi C, Meyers BM, Yoo J, Chan KKW; Head and Neck Disease Site Group. Systemic therapy in the curative treatment of head and neck squamous cell cancer: a systematic review. J Otolaryngol Head Neck Surg. 2017; 46:29.

13. Posner MR, Glisson B, Frenette G, Al-Sarraf M, Colevas AD, Norris CM, Seroskie JD, Shin DM, Olivares R, Garay CA. Multicenter phase I-II trial of docetaxel, cisplatin, and fluorouracil induction chemotherapy for patients with locally advanced squamous cell cancer of the head and neck. J Clin Oncol. 2001; 19:1096-1104.

14. Glisson BS, Murphy BA, Frenette G, Khuri FR, Forastiere AA. Phase II Trial of docetaxel and cisplatin combination chemotherapy in patients with squamous cell carcinoma of the head and neck. J Clin Oncol. 2002; 20:1593-1599.
15. Smith TJ, Khatcheressian J, Lyman GH, Ozer H, Armitage JO, Balducci L, Bennett CL, Cantor SB, Crawford J, Cross SJ, Demetri G, Desch CE, Pizzo PA, et al. 2006 update of recommendations for the use of white blood cell growth factors: an evidence-based clinical practice guideline. J Clin Oncol. 2006; 24:3187-3205.

16. Samlowski WE, Moon J, Kuebler JP, Nichols CR, Gandara DR, Ozer H, Williamson SK, Atkins JN, Schuller DE, Ensley JF. Evaluation of the combination of docetaxel/carboplatin in patients with metastatic or recurrent squamous cell carcinoma of the head and neck (SCCHN): a Southwest Oncology Group Phase II study. Cancer Invest. 2007; 25:182-188.

17. Takenaka Y, Cho H, Yamamoto M, Nakahara S, Yamamoto $\mathrm{Y}$, Inohara $\mathrm{H}$. Incidence and predictors of febrile neutropenia during chemotherapy in patients with head and neck cancer. Support Care Cancer. 2013; 21:2861-2868.

18. Sasaki T, Takenaka Y, Hayashi T, Yamamoto M, Cho H, Fukusumi T, Takemoto N, Hanamoto A, Yasui T, Nakahara S, Yamamoto Y, Mitani K, Inohara H. Factors predicting severe infections during chemotherapy in head and neck cancer patients. Acta Otolaryngol. 2015; 135:1086-1091.

19. Lyman GH, Dale DC, Friedberg J, Crawford J, Fisher RI. Incidence and predictors of low chemotherapy doseintensity in aggressive non-Hodgkin's lymphoma: a nationwide study. J Clin Oncol. 2004; 22:4302-4311.

20. Borg C, Ray-Coquard I, Philip I, Clapisson G, BendrissVermare N, Menetrier-Caux C, Sebban C, Biron P, Blay JY. CD4 lymphopenia as a risk factor for febrile neutropenia and early death after cytotoxic chemotherapy in adult patients with cancer. Cancer. 2004; 101:2675-2680.

21. Moreau M, Klastersky J, Schwarzbold A, Muanza F, Georgala A, Aoun M, Loizidou A, Barette M, Costantini S, Delmelle M, Dubreucq L, Vekemans M, Ferrant A, et al. A general chemotherapy myelotoxicity score to predict febrile neutropenia in hematological malignancies. Ann Oncol. 2009; 20:513-519.

22. Hosmer W, Malin J, Wong M. Development and validation of a prediction model for the risk of developing febrile neutropenia in the first cycle of chemotherapy among elderly patients with breast, lung, colorectal, and prostate cancer. Support Care Cancer. 2011; 19:333-341.

23. Schwenkglenks M, Pettengell R, Jackisch C, Paridaens R, Constenla M, Bosly A, Szucs TD, Leonard R. Risk factors for chemotherapy-induced neutropenia occurrence in breast cancer patients: data from the INC-EU Prospective Observational European Neutropenia Study. Support Care Cancer. 2011; 19:483-490.

24. Lyman GH, Kuderer NM, Crawford J, Wolff DA, Culakova E, Poniewierski MS, Dale DC. Predicting individual risk of neutropenic complications in patients receiving cancer chemotherapy. Cancer. 2011; 117:1917-1927.

25. Chia VM, Page JH, Rodriguez R, Yang SJ, Huynh J, Chao C. Chronic comorbid conditions associated with risk 
of febrile neutropenia in breast cancer patients treated with chemotherapy. Breast Cancer Res Treat. 2013; 138:621-631.

26. Bozcuk H, Yildiz M, Artac M, Kocer M, Kaya C, Ulukal E, Ay S, Kilic MP, Simsek EH, Kilickaya P, Ucar S, Coskun HS, Savas B. A prospectively validated nomogram for predicting the risk of chemotherapy-induced febrile neutropenia: a multicenter study. Support Care Cancer. 2015; 23:1759-1767.

27. Wang TY, Chen WM, Yang LY, Chen CY, Chou WC, Chen YY, Chen CC, Lee KD, Lu CH. Score of liver ultrasonography predicts treatment-related severe neutropenia and neutropenic fever in induction chemotherapy with docetaxel for locally advanced head and neck cancer patients with normal serum transamines. Support Care Cancer. 2016; 24:4697-4703.

28. Mizumachi T, Homma A, Kakizaki T, Sakashita T, Kano S, Hatakeyama H, Tsuchiya K, Yasuda K, Onimaru R, Shirato H, Taguchi J, Shimizu Y, Kinoshita I, et al. Feasibility and efficacy of induction docetaxel, cisplatin, and 5-fluorouracil chemotherapy combined with concurrent weekly cisplatin chemoradiotherapy for locally advanced head and neck squamous cell carcinoma. Int J Clin Oncol. 2015; 20:431-437.

29. Chen K, Zhang X, Deng H, Zhu L, Su F, Jia W, Deng X. Clinical predictive models for chemotherapy-induced febrile neutropenia in breast cancer patients: a validation study. PLoS One. 2014; 9:e96413.

30. Ogawa M. Differentiation and proliferation of hematopoietic stem cells. Blood. 1993; 81:2844-2853.

31. Ishizaka Y, Motoyoshi K, Hatake K, Saito M, Takaku F, Miura Y. Mode of action of human urinary colonystimulating factor. Exp Hematol. 1986; 14:1-8.

32. Wieser M, Bonifer R, Oster W, Lindemann A, Mertelsmann R, Herrmann F. Interleukin-4 induces secretion of CSF for granulocytes and CSF for macrophages by peripheral blood monocytes. Blood. 1989; 73:1105-1108.

33. Hamilton JA, Achuthan A. Colony stimulating factors and myeloid cell biology in health and disease. Trends Immunol. 2013; 34:81-89.

34. Hamilton JA. Colony-stimulating factors in inflammation and autoimmunity. Nat Rev Immunol. 2008; 8:533-544.

35. Auffray C, Sieweke MH, Geissmann F. Blood monocytes: development, heterogeneity, and relationship with dendritic cells. Annu Rev Immunol. 2009; 27:669-692.

36. Parihar A, Eubank TD, Doseff AI. Monocytes and macrophages regulate immunity through dynamic networks of survival and cell death. J Innate Immun. 2010; 2:204-215.

37. Moriyama Y, Horita N, Kudo M, Shinkai M, Fujita H, Yamanaka T, Ishigatsubo Y, Kaneko T. Monocyte nadir is a possible indicator for neutrophil nadir during lung cancer chemotherapy. Clin Respir J. 2017; 11:453-458.
38. Sugimoto Y, Katayama N, Masuya M, Miyata E, Ueno M, Ohishi K, Nishii K, Takakura N, Shiku H. Differential cell division history between neutrophils and macrophages in their development from granulocyte-macrophage progenitors. Br J Haematol. 2006; 135:725-731.

39. Kondo M, Oshita F, Kato Y, Yamada K, Nomura I, Noda K. Early monocytopenia after chemotherapy as a risk factor for neutropenia. Am J Clin Oncol. 1999; 22:103-105.

40. Oguz A, Karadeniz C, Ckitak EC, Cil V. Which one is a risk factor for chemotherapy-induced febrile neutropenia in childhood solid tumors: early lymphopenia or monocytopenia? Pediatr Hematol Oncol. 2006; 23:143-151.

41. Nathan C. Neutrophils and immunity: challenges and opportunities. Nat Rev Immunol. 2006; 6:173-182.

42. Jenkins P, Freeman S. Pretreatment haematological laboratory values predict for excessive myelosuppression in patients receiving adjuvant FEC chemotherapy for breast cancer. Ann Oncol. 2009; 20:34-40.

43. Lyman GH, Delgado DJ. Risk and timing of hospitalization for febrile neutropenia in patients receiving CHOP, CHOP-R, or CNOP chemotherapy for intermediate-grade non-Hodgkin lymphoma. Cancer. 2003; 98:2402-2409.

44. Ray-Coquard I, Borg C, Bachelot T, Sebban C, Philip I, Clapisson G, Le Cesne A, Biron P, Chauvin F, Blay JY. Baseline and early lymphopenia predict for the risk of febrile neutropenia after chemotherapy. Br J Cancer. 2003; 88:181-186.

45. Alexandre J, Rey E, Girre V, Grabar S, Tran A, Montheil V, Rabillon F, Dieras V, Jullien V, Herait P, Pons G, Treluyer JM, Goldwasser F. Relationship between cytochrome 3A activity, inflammatory status and the risk of docetaxelinduced febrile neutropenia: a prospective study. Ann Oncol. 2007; 18:168-172.

46. Ozawa K, Minami H, Sato H. Logistic regression analysis for febrile neutropenia (FN) induced by docetaxel in Japanese cancer patients. Cancer Chemother Pharmacol. 2008; 62:551-557.

47. Hershman D, Hurley D, Wong M, Morrison VA, Malin JL. Impact of primary prophylaxis on febrile neutropenia within community practices in the US. J Med Econ. 2009; 12:203-210.

48. Chan A, Chen C, Chiang J, Tan SH, Ng R. Incidence of febrile neutropenia among early-stage breast cancer patients receiving anthracycline-based chemotherapy. Support Care Cancer. 2012; 20:1525-1532.

49. Corre F, Lellouch J, Schwartz D. Smoking and leucocytecounts. Results of an epidemiological survey. Lancet. 1971; 2:632-634.

50. Hoyer JD. Leukocyte differential. Mayo Clin Proc. 1993; 68:1027-1028.

51. Witko-Sarsat V, Rieu P, Descamps-Latscha B, Lesavre P, Halbwachs-Mecarelli L. Neutrophils: molecules, functions and pathophysiological aspects. Lab Invest. 2000; 80:617-653. 
52. Aapro MS, Bohlius J, Cameron DA, Dal Lago L, Donnelly JP, Kearney N, Lyman GH, Pettengell R, Tjan-Heijnen VC, Walewski J, Weber DC, Zielinski C, European Organisation for R, Treatment of C. 2010 update of EORTC guidelines for the use of granulocyte-colony stimulating factor to reduce the incidence of chemotherapy-induced febrile neutropenia in adult patients with lymphoproliferative disorders and solid tumours. Eur J Cancer. 2011; 47:8-32.

53. Kiura K. [Overview of guidelines for proper use of the G-CSF(2013 edition)]. [Article in Japanese]. Gan To Kagaku Ryoho. 2014; 41687-90. Gan To Kagaku Ryoho. 2014; 41:687-690. 